\title{
IMPACT OF A SINGLE TUTORIAL SESSION ON THE TECHNIQUE OF USING PERSONAL PROTECTIVE EQUIPMENT BY HEALTH CARE WORKERS
}

\author{
Jamal Azfar Khan, Asif Ali, Farzana Muneer* \\ Combined Military Hospital Landi Kotal/National University of Medical Sciences (NUMS) Pakistan, *Tehsil Headquarter Hospital, \\ Layyah Pakistan
}

\begin{abstract}
Objective: To determine the impact of a single tutorial session on the technique of donning and doffing the personal protective equipment by health care workers.

Study Design: Cross-sectional comparative study.

Place and Duration of Study: Combined Military Hospital, Landi Kotal Cantt, from Mar 2020 to Jun 2020.

Methodology: Sixty two health workers were asked to demonstrate donning and doffing surgical mask, gown and gloves, and the steps were evaluated as per a standardized checklist. Then, the participants were given a single tutorial for the donning and doffing technique of personal protective equipment. They were asked to demonstrate the technique of personal protective equipment use one week, one month and three months after the tutorial. Any improvement was recorded in the checklist used earlier.

Results: The correct donning and doffing technique of personal protective equipment was demonstrated by 22 $(35.5 \%)$ and $14(22.6 \%)$ participants respectively before the tutorial. When evaluated one week after the tutorial, this number increased to $48(77.4 \%)$ and $38(61.3 \%)$ respectively, showing significant improvement $(p<0.05)$. The technique of personal protective equipment use deteriorated significantly one month after the tutorial and deteriorated further after three months $(p<0.05)$. The most common fault while donning and doffing the equipment was the incorrect donning sequence, and self-contamination while taking off the gloves, demonstrated by 38 $(61.3 \%)$ and $47(75.8 \%)$ participants, respectively.

Conclusion: A single tutorial session results in significant improvement in the technique of using personal protective equipment by health care workers but the effect was lost over time.
\end{abstract}

Keywords: Gloves, Health personnel, Masks, Personal protective equipment.

This is an Open Access article distributed under the terms of the Creative Commons Attribution License (http://creativecommons.org/licenses/by/4.0), which permits unrestricted use, distribution, and reproduction in any medium, provided the original work is properly cited.

\section{INTRODUCTION}

The spread of infection in a health care facility is a major concern for health care workers (HCW) all over the world. Infections can spread from patient to patient, patient to HCW or HCW to patient ${ }^{1}$. This can lead to a prolonged stay of the patient in the hospital, increased mortality and morbidity and an enormous increase in the cost of health care ${ }^{2}$. Thus, it is very important to prevent the spread of infections for patient safety as well as the wellbeing of the HCW.

Health care facilities all over the world adopt various methods and protocols to curb the spread of infections. One of them is the use of Personal Protective Equipment $(\mathrm{PPE})^{3}$. Serious infections

Correspondence: Dr Jamal Azfar Khan, Department of Internal Medicine, CMH Landi Kotal, Cantt Pakistan

Received: 09 Jun 2020; revised received: 11 Jul 2020; accepted: 19 Aug 2020 can be prevented if the HCWs use PPE judiciously and practice hand washing 4 . The importance of use of PPE has recently been highlighted again during the outbreak of coronavirus disease (COVID-19) which is caused by severe acute respiratory syndrome- coronavirus 2 (SARS-CoV$2)^{5}$. As the COVID-19 infection has spread phenomenally and become a pandemic, many HCW have also been infected. Thus, the guidelines issued by Ministry of Health, Regulation and Coordination, Government of Pakistan, ${ }^{6}$, as well as WHO guidelines 7 , advise the HCWs to use PPE, including gloves, face masks and gowns while dealing with COVID-19 patients.

It is usually taken for granted that HCWs are well versed with the appropriate use of PPE and that they have been properly trained in this aspect. Some health workers may never have 
been trained in the proper use of PPE. Thus, to gauge the proficiency in PPE use amongst HCWs, we conducted this research study. We hypothesized that the HCWs (doctors, nurses, nursing assistants and auxiliary staff) were not conversant with the proper technique of donning and doffing PPE. We further hypothesized that even a single practical tutorial session instructing the HCWs regarding the proper technique will result in sustained improvement in their PPE donning and doffing skills.

\section{METHODOLOGY}

This was a cross-sectional comparative study carried out in Combined Military Hospital, Landi Kotal from 1st March 2020 to 10th June 2020. We took approval to carry out the research study from the hospital's Ethics Review Board (Letter ref \# 01/2020 dated 20 Feb, 2020). We employed the total population sampling strategy wherein we recruited all the HCWs performing their duties in the Emergency Department, Department of Medicine and Intensive Care Unit of the hospital. These departments were selected because the HCWs working there would be the ones dealing with COVID-19 patients. We used the total population sample because of the small size of the population under study ${ }^{8}$. Informed consent was taken from the participants in the study. The participants were first interviewed to ascertain their age, sex, years of service and field of work. They were also asked whether they had received prior formal training in the use of PPE. If they had, they were asked what the mode of instruction was (theoretical or practical) and how long it had been since they got that training. They were then asked to demonstrate how to don and doff PPE, which included face masks, gloves and gowns. The technique was assessed using a standardized checklist used in John et al's study ${ }^{9}$ (fig-1). This checklist was based on CDC recommendations for PPE use ${ }^{10}$.

With the help of this checklist, we found out which steps of the donning and doffing procedures were performed incorrectly. Afterwards, we provided a tutorial session for the participants of the study. First, we educated them about the proper donning and doffing of PPE as per CDC guidelines ${ }^{10}$, with the help of Power Point slides and practical demonstration. This was followed by a hands-on practice session. The participants were divided into batches of six. Each participant was given individual attention until he/she started donning and doffing the PPE as per CDC guidelines.

After one week, the participants were asked to demonstrate the donning and doffing of PPE. Their technique was evaluated using the same

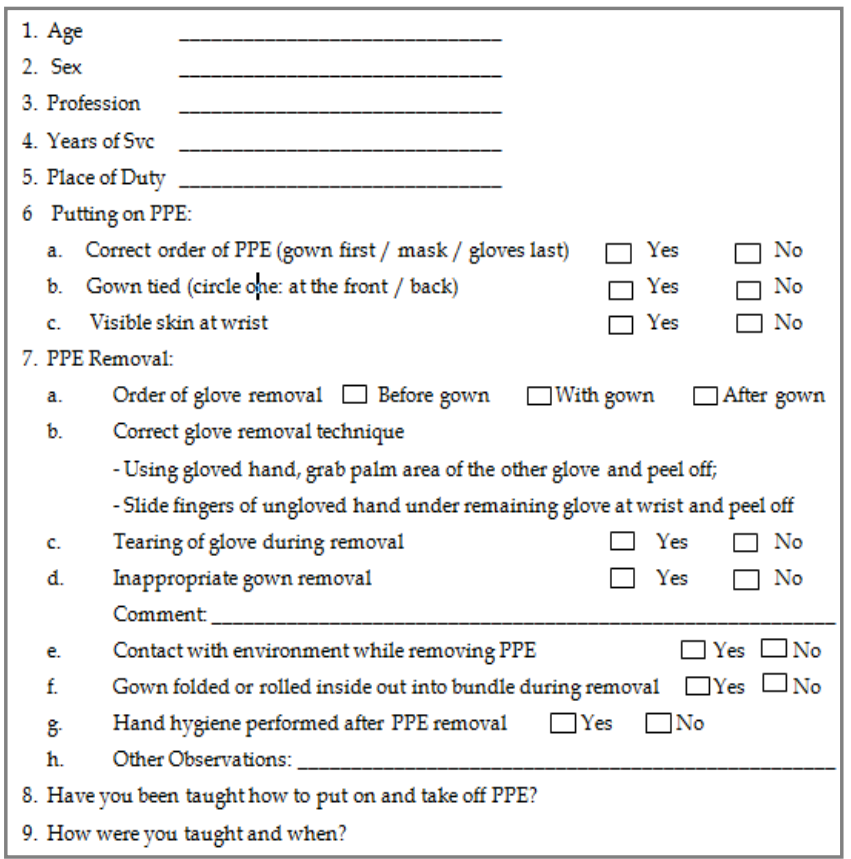

Figure-1: Checklist for personal protective equipment donning and doffing.

checklist that was used earlier. If a participant performed even a single step incorrectly, the technique was regarded as flawed. This was done because even a single faulty step would result in contamination of the body/ clothes of the HCW 11. This evaluation of PPE donning and doffing technique was repeated one month and three months after the tutorial session, to determine the extent to which the instructions given in the tutorial were followed over a while.

The data was analyzed using SPSS version 23. We looked for any improvement in the PPE donning and doffing technique after the single 
tutorial session by comparing the technique before the tutorial with the technique one week afterwards. We also evaluated whether the improvement was sustained over some time by comparing the results from one week after the tutorial with the results one month and three months afterwards. We used McNemar test for paired samples to determine if the difference of results was significant. A $p$-value $<0.05$ was considered statistically significant.

\section{RESULTS}

There were 62 participants in the study. Out of them, $53(85.5 \%)$ were male and $9(14.5 \%)$ were females. There were $8(12.9 \%)$ doctors, $3(4.8 \%)$

Table-I: Correct donning technique of Personal Protective Equipment before training \& one week after training.

\begin{tabular}{|c|c|c|c|c|}
\hline \multirow[b]{2}{*}{$\begin{array}{l}\text { Before } \\
\text { Training }\end{array}$} & \multicolumn{3}{|c|}{ One Week After Training } & \multirow[b]{2}{*}{$\begin{array}{c}p- \\
\text { value }\end{array}$} \\
\hline & $\begin{array}{c}\text { Incorrect } \\
\text { Procedure } \\
\text { n (\%) }\end{array}$ & $\begin{array}{l}\text { Correct } \\
\text { Procedure } \\
\text { n }(\%)\end{array}$ & $\begin{array}{l}\text { Total } \\
\text { n ( } \%)\end{array}$ & \\
\hline $\begin{array}{l}\text { Incorrect } \\
\text { Procedure }\end{array}$ & $14(22.6)$ & $26(41.9)$ & $40(64.5)$ & \multirow{3}{*}{$<0.01$} \\
\hline $\begin{array}{l}\text { Correct } \\
\text { Procedure }\end{array}$ & - & $22(35.5)$ & $22(35.5)$ & \\
\hline Total & $14(22.6)$ & $48(77.4)$ & $62(100)$ & \\
\hline
\end{tabular}

Table-II: Correct doffing technique of Personal Protective Equipment before training \& one week after training.

\begin{tabular}{|c|c|c|c|c|}
\hline \multirow[b]{2}{*}{$\begin{array}{l}\text { Before } \\
\text { Training }\end{array}$} & \multicolumn{3}{|c|}{ One Week After Training } & \multirow[b]{2}{*}{$\begin{array}{c}p- \\
\text { value }\end{array}$} \\
\hline & $\begin{array}{c}\text { Incorrect } \\
\text { Procedure } \\
\text { n (\%) }\end{array}$ & $\begin{array}{l}\text { Correct } \\
\text { Procedure } \\
\text { n (\%) }\end{array}$ & $\begin{array}{l}\text { Total } \\
\text { n ( } \%)\end{array}$ & \\
\hline $\begin{array}{l}\text { Incorrect } \\
\text { Procedure }\end{array}$ & $24(38.7)$ & $24(38.7)$ & $48(77.4)$ & \multirow{3}{*}{$<0.01$} \\
\hline $\begin{array}{l}\text { Correct } \\
\text { Procedure }\end{array}$ & - & $14(22.6)$ & $14(22.6)$ & \\
\hline Total & $24(38.7)$ & $38(61.3)$ & $62(100)$ & \\
\hline
\end{tabular}

nurses and 51 (82.2\%) auxiliary staff, including nursing assistants, operation room assistants and "Ayahs" (helpers). The age of the participants ranged from 23 to 50 years, mean being $31 \pm 6.94$ years. The participants had years of service ranging from 2 to 19 years, mean being $9 \pm 4.5$ years.

Out of the 62 participants, $54(87 \%)$ had received instructions regarding donning and doffing of PPE. The instructions had been in the form of a practical demonstration by a co-worker or senior during work. Instruction regarding PPE use had not been part of any formal classroom lecture nor had it been evaluated in any exam. All those who had received some form of tutorial or demonstration had received it during the initial year of practice, 3 to 19 years ago, mean duration since last training being $8.5 \pm 3.6$ years. Eight (13\%) participants did not recall any training, either theoretical or practical, regarding the correct technique of donning and doffing PPE. All of these eight were paramedics or Ayahs.

When demonstrating donning of PPE initially, only 22 participants (35.5\%) demonstrated the

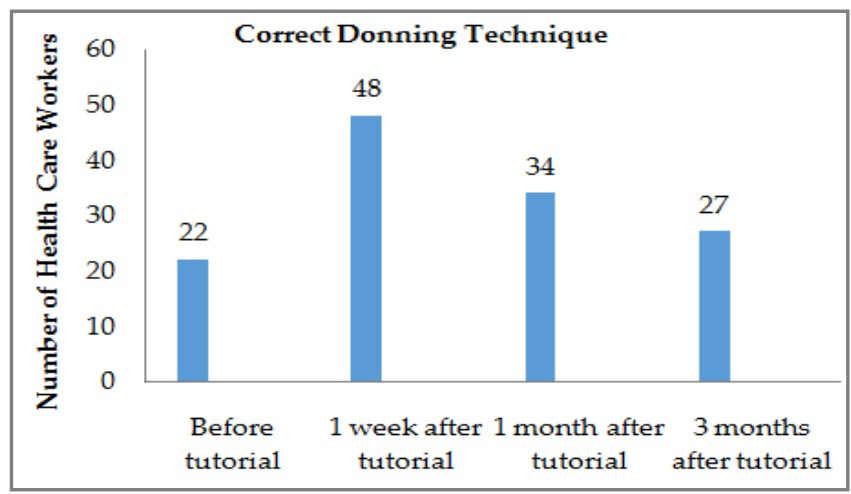

Figure-2: Number of health care workers demonstrating correct personal protective equipment donning technique.

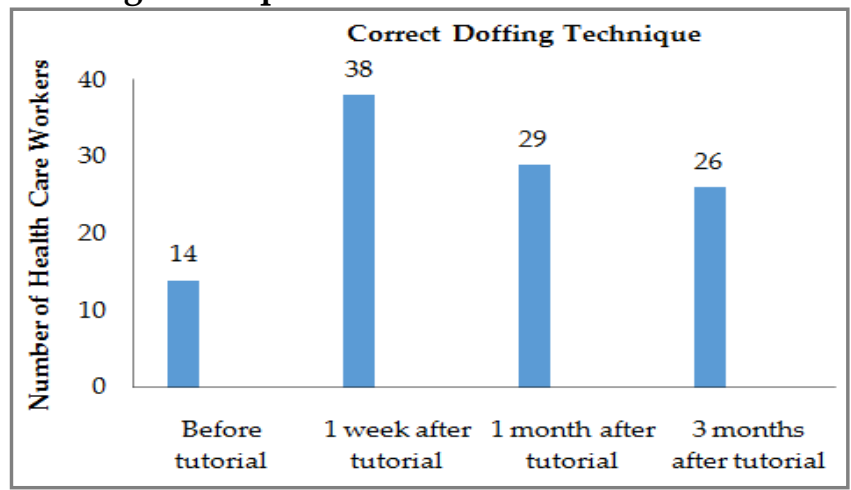

Figure-3: Number of health care workers demonstrating correct personal protective equipment doffing technique.

correct technique while 40 participants (64.5\%) performed one or more steps incorrectly. The most common mistake was the incorrect sequence of putting on PPE, demonstrated by 38 $(61.3 \%)$ participants. When evaluated one week 
after attending the tutorial session, 48 participants $(77.4 \%)$ performed all the steps correctly. The difference between the two performances was statistically significant $(p<0.01)$. The cross tabulation data for donning of PPE before and one week after the tutorial is shown in table-I.

The number of participants demonstrating correct PPE donning technique fell to 34 (54.8\%) after one month, and to $27(43.5 \%)$ after three months of the tutorial, as shown in fig- 2 .

This decline at one month and three months was statistically significant $(p<0.01)$ when compared to the 1-week post-tutorial results. However, when we compared the results from before the tutorial with the results three months afterwards, they were not statistically significant $(p=0.424)$.

The PPE doffing technique was observed before and after the tutorial in the same way. Before receiving the tutorial, only 14 participants $(22.6 \%)$ performed all the steps correctly and in the correct order. The most common mistake made was the incorrect technique of taking the gloves off, resulting in self-contamination which was demonstrated by $47(75.8 \%)$ participants. One week after the tutorial session, 38 participants $(61.3 \%)$ demonstrated the correct doffing technique. The improvement in the result was statistically significant $(p<0.01)$. The cross tabulation data for doffing of PPE before and 1 week after the tutorial is shown in table-II.

After one month, the number dropped to 29 $(46.8 \%)$ and after three months, to $26(41.9 \%)$, as shown in fig-3.

The decline after one month and three months, as compared to the initial post-tutorial results was statistically significant $(p=0.002$ and 0.001 respectively). When the pre-tutorial and 3months post-tutorial results were compared, the participants still showed statistically significant improvement in PPE doffing technique $(p=0.002)$.

\section{DISCUSSION}

Personal protective equipment is used by health care workers in emergency departments, laboratories, operation theaters, intensive care units, etc. Even with such extensive use, numerous studies have reported that HCWs do not practice the correct technique when putting on or taking off PPE12-15. In our study, we also found out that the majority of HCWs demonstrated faulty PPE donning and doffing techniques. Thus our study corroborates the result of previous such studies.

The most common fault during PPE donning was that the order in which various items were put on was wrong. As per CDC guidelines, the gown should be donned first, followed by the mask (and goggles) and the gloves should be worn in the end. This sequence is important to keep the gloves "clean", meaning to say that the chances of the gloves getting soiled or contaminated are kept at a minimum by donning them last of all. Likewise, when taking the PPE off, the gloves should be doffed first, and with care so as not to contaminate the skin or clothes, as the gloves are the most contaminated among the PPEs. Thus, this step is very important and is the one performed incorrectly most often. There are many studies which have reported self-contamination to be a common error made while taking the gloves off 16,17 . Our study confirms the same result.

The reason behind the frequent errors in using PPE may be lack of formal training ${ }^{2}$, as PPE use is not formally taught in the majority of medical schools9. Most HCWs only receive informal training in PPE use, mainly in the form of an "on job training" by a colleague or a senior ${ }^{18}$. The situation is the same for paramedical staff. Thus, the casual method of the trainer or the trainee may be responsible for the adoption of wrong practices of using PPE. Secondly, PPE is not as commonly used in our health care facilities as it ought to be ${ }^{19}$. The reason for this underuse might be the lack of health care workers' insight into its importance in preventing infections or a lack of resources. The lack of resources is a significant cause in low-to-middle income countries ${ }^{2}$ such as Pakistan. In this regard, a systematic review was conducted by Chughtai et al ${ }^{20}$ regarding PPE use in Pakistani hospitals, dental clinics and labora- 
tories. The study revealed that personal protective equipment was simply not available in manyhealth care facilities. Even when available, the HCWs do not always use them as they are either "saving" them for more important procedures or simply do not care to use them as a routine precaution against disease transmission.

We demonstrated in our study that even a single intervention in the form of a tutorial session regarding the correct PPE donning and doffing technique can improve the HCWs' skills in using PPE significantly. There have been other studies with similar results, demonstrating the effectiveness of a single tutorial session in improving the participants' practices ${ }^{21}$. A study carried out by Díaz-Guio et al compared the PPE donning and doffing technique of HCWs before and after a tutorial in the form of a clinical simulation exercise $^{22}$. They observed $100 \%$ success in donning and $94.8 \%$ in doffing of PPE whereas none of the participants had been successful in donning or doffing the PPE satisfactorily before the tutorial. Tomas et al also demonstrated that the self-contamination rate among HCWs dropped from $60 \%$ to $18.9 \%$ after a single training session ${ }^{23}$.

The HCWs have to be trained regularly in the use of PPE or else the skill may be lost over time. It is well known that people maintain their knowledge and skills throughrepetition and practice. Our study revealed that the majority of the participants had received training of using PPE only in the initial years of service. When they went through training as a part of this study, their technique of using PPE improved significantly. However, it deteriorated significantly over the next three months. This emphasizes the need of repeated training sessions for HCWs to maintain their competence in PPE use. Hospitals usually run regular training courses for some essential skills like basic life support and advanced cardiac life support courses ${ }^{24}$. This ensures that these skills are not lost over time. In the same way, if HCWs are taught about PPE use and the correct donning/doffing techniques regularly, we can expect HCWs to have continued competence in these skills. Alhmidi et al demonstrated the improvement in the participants' PPE donning and doffing technique after a single tutorial session, and suggested to conduct training sessions at regular intervals and during outbreaks to maintain the skill level of the HCWs ${ }^{24}$.

The correct use of PPE is an immensely important skill to acquire for any health worker. Thus, it should ideally be taught at an early level during health care workers' training. Milward et $a{ }^{25}$ demonstrated in their study that if the infection competency training is imparted at undergraduate level, it provided lasting knowledge and practical benefit to the students. John et al reported that $59 \%$ of undergraduate students had not had any sort of training in PPE usage 9 . Thus, we recommend that the training for PPE donning and doffingto beincluded in the undergraduate medical curriculum, followed by refresher sessions at regular intervals. It is likely to benefit the medical personnel and their patients in the long run.

\section{LIMITATION OF STUDY}

In our study, the sample size was small and the participants were from only those departments of the hospital which regularly deal with infectious patients. The HCWs working in these departments may have a different attitude towards PPE use as compared to other departments that do not deal with emergencies very frequently and regularly. Thus, the participants of our study may be using PPE more often to prevent getting infected from patients and thus, their proficiency in using PPE cannot be generalized. Further study needs to be conducted, in multiple departments and preferably in multiple centers, to ascertain the actual level of competence of PPE use among health care professionals.

Secondly, the HCWs might have performed the PPE donning and doffing differently as compared to their usual practices as they knew that they were being watched. This bias in the results cannot be ruled out.

\section{ACKNOWLEDGEMENT}

We acknowledge the contribution of Amna Mahmood in data analysis. 


\section{CONCLUSION}

The majority of HCWs do not use the correct technique of donning and doffing PPE. A single practical tutorial session instructing the HCWs regarding the proper technique results in improvement in their PPE donning and doffing skills. However, this improvement is not sustained over some time.

\section{CONFLICT OF INTEREST}

This study has no conflict of interest to be declared by any author.

\section{REFERENCES}

1. Brosio F, Kuhdari P, Stefanati A, Sulcaj N, Lupi S, Guidi E, et al. Knowledge and behaviour of nursing students on the prevention of healthcare associated infections. Int J Prev Med 2017; 58(2): e99-e104.

2. Alp E, Damani N. Healthcare-associated infections in intensive care units: epidemiology and infection control in low-to-middle income countries. J Infect Dev Ctries 2015; 9(10): 1040-45.

3. Brown L, Munro J, Rogers S. Use of personal protective equipment in nursing practice. J Nurs Stand 2019; 34(5): 59-66.

4. Link T. Guideline Implementation: Transmission-Based Precautions. AORN J 2019; 110(6): 637-49.

5. Thomas-Ruddel D, Winning J, Dickmann P, Ouart D, Kortgen A, Janssens U, et al. Coronavirus disease 2019 (COVID-19): update for anesthesiologists and intensivists March 2020. Der Anaesthesist. 2020; 69(4): 225-35.

6. Ministry of National Health Services Regulation and Coordination. 2019-nCoVirus Clinical Care \& Prevention GoP Guidelines 2020: 7.

7. World Health Organization. Infection prevention and control during health care when COVID-19 is suspected. 2020: 2.

8. Laerd dissertation. Purposive sampling: Lund Research Ltd; 2012. Available from: http://dissertation.laerd.com/purposivesampling.php\#total.

9. John A, Tomas ME, Hari A, Wilson BM, Donskey CJ. Do medical students receive training in correct use of personal protective equipment? Med Educ Online 2017; 22(1): 1264125.

10. Centers for Disease Control and Prevention. Sequence for putting on personal protective equipment and how to safely remove personal protective equipment. 2014. p. 1-3.

11. Pang V, Carter Y, Scott J, Salazar G, Johnson V. How to use personal protective equipment. Nurs Times 2014; 110(51): 14-16.

12. Doll M, Feldman M, Hartigan S, Sanogo K, Stevens M, Mc-
Reynolds M, et al. Acceptability and Necessity of Training for Optimal Personal Protective Equipment Use. Infect Control Hosp Epidemiol 2017; 38(2): 226-29.

13. Mulvey D, Mayer J, Visnovsky L, Samore M, Drews F. Frequent and unexpected deviations from personal protective equipment guidelines increase contamination risks. Am J Infect Control 2019; 47(9): 1146-47.

14. Beam EL, Gibbs SG, Boulter KC, Beckerdite ME, Smith PW. A method for evaluating health care workers' personal protective equipment technique. Am J Infec Control 2011; 39(5): 415-20.

15. Shrestha GDN, Thapa B. Knowledge and practice on infection prevention among nurses of bir hospital, Kathmandu. J Nepal Health Res Counc 2018; 16(3): 330-35.

16. Okamoto K, Rhee Y, Schoeny M, Lolans K, Cheng J, Reddy S, et al. Impact of doffing errors on healthcare worker self-contamination when caring for patients on contact precautions. Infect Control Hosp Epidemiol 2019; 40(5): 559-65.

17. Chughtai AA, Chen $X$, Macintyre CR. Risk of self-contamination during doffing of personal protective equipment. Am J Infect Control 2018; 46(12): 1329-34.

18. John A, Tomas ME, Cadnum JL, Mana TS, Jencson A, Shaikh A, et al. Are health care personnel trained in correct use of personal protective equipment? Am J Infect Control 2016; 44(7): 840-42.

19. Menonna-Quinn D, Polovich M, Marshall B. Personal protective equipment: evaluating usage among inpatient and outpatient oncology nurses. Clin J Oncol Nurs 2019; 23(3): 260-65.

20. Chughtai AA, Khan W. Use of personal protective equipment to protect against respiratory infections in Pakistan: A systematic review. J Infect Public Health 2020; 13(3): 385-90.

21. Hon CY, Gamage B, Bryce EA, LoChang J, Yassi A, Maultsaid D. Personal protective equipment in health care: can online infection control courses transfer knowledge and improve proper selection and use? Am J Infect Control 2008; 36(10): e33-37.

22. Díaz-Guio DA, Ricardo-Zapata A, Ospina-Velez J, GómezCandamil G, Mora-Martinez S, Rodriguez-Morales AJ. Cognitive load and performance of health care professionals in donning and doffing PPE before and after a simulation-based educational intervention and its implications during the COVID-19 pandemic for biosafety. Le infezioni Medicina 2020; 28 (Suppl-1): 111-17.

23. Tomas ME, Kundrapu S, Thota P, Sunkesula VC, Cadnum JL, Mana TS, et al. Contamination of health care personnel during removal of personal protective equipment. J Am Med Assoc Internal Med 2015; 175(12): 1904-10.

24. Ziabari SMZ, Kasmaei VM, Khoshgozaran L, Shakiba M. Continuous education of basic life support (BLS) through social media; a quasi-experimental study. Arch Academic Emerg Med 2019; 7(1): e4-10.

25. Milward MR, Cooper PR. Competency assessment for infection control in the undergraduate dental curriculum. Eur J Dental Edu 2007; 11(3): 148-54. 